\title{
Foresight of Volga Federal District Innovation System Development using a Multi-Objective Genetic Algorithm
}

\author{
Sergei Yashin ${ }^{1}$, Nadezhda Yashina ${ }^{2}$, Egor Koshelev${ }^{1}$, Oksana Kashina ${ }^{2}$, Natalia \\ Pronchatova-Rubtsova ${ }^{2 *}$ \\ ${ }^{1}$ Department of Management and Public Administration, The Institute of Economics and Entrepreneurship, \\ Lobachevsky University, 23 Gagarin Ave, 603950, Nizhni Novgorod, Russia \\ ${ }^{2}$ Department of Finance and Credit, The Institute of Economics and Entrepreneurship, Lobachevsky \\ University, 23 Gagarin Ave, 603950, Nizhni Novgorod, Russia
}

\begin{abstract}
The application of simulation modeling in public administration is under study at the level of interregional interaction in specific federal districts. The main indicator for development success of a particular federal district is the natural growth of its population. For this purpose, a model of foresight of federal district innovation system development based on the use of a multi-objective genetic algorithm was proposed. Stages of this foresight included preparation of statistical data for clusters, obtaining predictive functions for clusters and Pareto frontiers of predictive functions, and planning synergy effects of clusters of regions and the entire federal district. In this case, to increase the synergy effect of a federal district, investment resources and research and development (R\&D) costs were planted to be redirected to those regions where economic and financial resources are insufficient. This will eventually increase the average per capita income of the population in the regions of the federal district, which will lead to population growth in these regions. If R\&D costs are redistributed, there are also information and logistics interactions that confirm the practical effectiveness of the open innovation model within the federal district. For the Volga Federal District, this foresight resulted in its total positive reserve for R\&D in the amount of 8,412 million rubles. It should be forwarded to the Samara Region. Then, the synergy effect of the whole Volga Federal District will be equal to 429,344 million rubles.
\end{abstract}

Keywords: Foresight; Intercluster interaction; Multi-objective genetic algorithm; Simulation modeling

\section{Introduction}

Currently, fundamental research on strategic development issues is increasingly moving into the subject area of regional economics (Rodionov and Velichenkova, 2020; Rytova and Gutman, 2020). At the present time, one of the most important approaches includes the introduction of technologies for simulation modeling in business processes based on the handling of bulk data (Big Data) and its application to the analysis of regional cluster data (Kudryavtseva et al., 2020b). The creation and promotion of clusters in the Russian Federation is one of the main aims of the Russian government and is supported by two governmental programs: the program of the Ministry of Economic Development of the Russian Federation "Pilot innovative territorial clusters" and The Program of the Ministry

${ }^{*}$ Corresponding author's email: pronat89@mail.ru, Tel.: +7-904-900-26-65

doi: 10.14716/ijtech.v11i6.4432 
of Industry and Trade of the Russian Federation "Industrial clusters". Since the debate on the measurement of cluster performance is ongoing in the EU (Ketels and Protsiv, 2020), USA (Delgado et al., 2016), Russia (Stepanova, 2019), and other countries, it is essential to provide adequate approaches and tools for analysis of regional cluster development (Kudryavtseva et al., 2020a). One of the possible solutions to this problem could be the application of Genetic algorithms (Snytyuk and Suprun, 2017).

Genetic algorithm (GA) is an evolutionary search method used to solve optimization problems using mechanisms similar to biological evolution (Holland, 1992; Chen et al., 2011). The genetic algorithm itself consists of several steps: (1) preparatory step formation of an initial population; (2) selection; (3) cross breeding; (4) mutation; and (5) solution evaluation and algorithm stopping (Morov, 2012). An important concept in GA is the fitness function, otherwise known as the evaluation function. It represents a measure of fitness for a certain individual in the population. In optimization problems, the fitness function is usually maximized and called an objective function (Rutkowska et al., 1999). Tate and Smith (1995) developed a standard GA. In this, they implemented mutation and cross breeding independently of each other, unlike most GA implementations, where mutation is used as an auxiliary procedure for individuals in the population. The algorithm used a chromosome mutation with a paired exchange (Kravets and Safronova, 2013). Many other modifications were developed for the GA, for example, greedy GA (Ahuja et al., 1995) and self-adapting algorithms with the application of heterogeneous mutations (Michalewicz, 1996), among others. Evolutionary algorithms are relatively new but are very powerful methods used to find solutions to many real search and optimization problems. Many of these problems have multiple objectives, resulting in the need for a set of optimal solutions, known as effective solutions (Nasruddin et al., 2018). The use of evolutionary algorithms is a highly effective way to find many effective solutions in a single simulation run (Kalyanmoy, 2001).

This paper suggests the application of simulation modeling at the level of interregional interaction in the Volga Federal District of Russian Federation using GA.

\section{Methods}

Yashin et al. (2017) suggested foresight methods based on predicting values of capitalization functions of the cluster companies and on calculating the best possible equivalent portfolio of the cluster companies using arbitrage techniques. Foresight is a set of approaches providing conditions for long-term forecasting of situations, while making strategic decisions (Martin, 1983, 1989, 2010; Tukkel et al., 2013). However, these methods are not effective enough for the foresight of development of major innovation systems, which include the federal districts of the country. In this case, it is necessary to consider various effects of intercluster interactions, which include economic, financial, informational and logistics interactions. Thus, considering the latter results, proposed a foresight model of federal district innovation system development based on the use of a multi-objective genetic algorithm (MGA). This method is principally new to the foresight of big innovational systems. The stages of this foresight are shown in Figure 1.

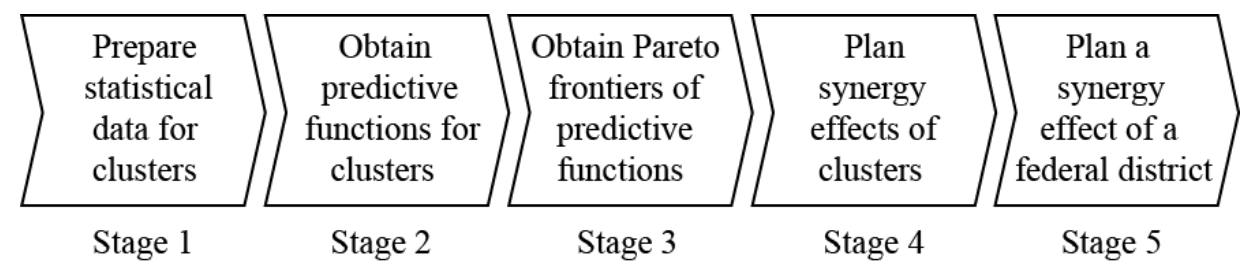

Figure 1 Stages of foresight of the federal district innovation system development 
Since the paper by Yashin et al. (2019) established that the greatest influence on the natural growth of the population is exerted by the average per capita cash income of the population (per month), we primarily focused on maximizing this function $\left(y_{1}\right)$ in each region of the federal district, where there are innovative and industrial clusters. The other two factors that we considered when building the model were investment in equity $\left(y_{2}\right)$ and internal current expenditure on research and development (R\&D) $\left(y_{3}\right)$.

In this case, we embraced intercluster interactions in three previously identified areas, namely economic, financial, informational and logistics, as the identified reserve for the functions $y_{2}$ and $y_{3}$ with the view of increasing the synergy effect of the federal district planned to be redirected to those regions where there is a shortage of economic and financial resources. This will eventually increase the average per capita income of the population in these regions, which will lead to population growth. If $R \& D$ costs are redistributed in a similar manner, there are information and logistics interactions that confirm the practical effectiveness of the open innovation model within the federal district.

Turning to the essence of the proposed foresight model, we described its stages as shown in Figure 1.

Stage 1 - Prepare Statistical Data for Clusters. We already identified the three main components of the model as $y_{1}, y_{2}$, and $y_{3}$. However, due to the fact that this data contained annual information about 25 clusters located in the Volga Federal Region from 2009 to 2018, which is presented in money, it needs to be adjusted for inflation. Then, the real dynamics of these indicators can be seen.

Stage 2 - Obtain Predictive Functions for Clusters. It is these functions for $y_{1}, y_{2}$, and $y_{3}$ that were used to implement a multi-objective genetic algorithm, so it is important to build them as reliably as possible. For this purpose, we focused on the value of the determination coefficient $R^{2}$.

Stage 3 - Obtain Pareto Frontiers of Predictive Functions. For this purpose, we used a multi-objective genetic algorithm. This foresight stage is central from a technological perspective.

Let us assume that we want to maximize several objective functions simultaneously, each with a global extremum. Objective functions have their own individual extrema. However, in a multi-objective problem, any solution in the range between limiting function extrema is equally optimal. There is no single solution to this multi-objective problem. The goal of a multi-objective genetic algorithm is to find a set of solutions in a given range, ideally with a good spread. A solution set is also known as a Pareto frontier. All solutions at the Pareto frontier are optimal.

We used visualization of two graph options. The first option built a Pareto frontier (limited to any three objectives) for each generation. The second option built an interval from the global extremum of each analyzed function to the other limiting extremum of the corresponding graph function.

Stage 4 - Plan Synergy Effects of Clusters. A detailed Pareto frontier analysis for a particular region determined the optimal value of the average per capita monetary income of its population $\left(y_{1}\right)$. For the obtained income, it was possible to determine the planned indicators $y_{2}$ and $y_{3}$. Then the maximum possible synergy effect for each region, where there were innovative and industrial clusters, was calculated by the formula:

$$
S=y_{2, \text { plan }}-y_{2, \text { fact }}+y_{3, \text { plan }}-y_{3, \text { fact }} \text {, }
$$

where planned values were received in accordance with the MGA, while the actual values were taken from the last analyzed year. 
Stage 5 - Plan a Synergy Effect of a Federal District. If for a particular region there was an excess of the actual value over the planned one in terms of $y_{2}$ or $y_{3}$, we considered this difference as a reserve. It was redirected to those regions where there was an excess of the planned value over the actual one in terms of $y_{2}$ or $y_{3}$. This, in turn, adjusted the synergy effects of the regions that received the funds. Such mechanisms of redistribution of investment in equity and expenditures on R\&D enabled the federal district to develop a partially closed innovation system with a decrease in external federal and private financing.

As a result, the method for assessment of the synergy effect was adjusted for each region receiving funds by the amount of the reserve obtained from reserve donor regions, i.e.,

$$
S_{n e w}=y_{2 . p l a n}-y_{2 . f a c t}+y_{3, \text { plan }}-y_{3, \text { fact }}-\sum_{i=1}^{n} R_{i},
$$

where $R_{i}$ is the value of the reserve obtained from the $i$-th donor region (million rubles) and $n$ is the number of regions in the federal district that have innovative and industrial clusters.

After that, the adjusted synergy effects of the regions were summed up, and the maximum possible synergy effect was obtained for the entire federal district:

$$
S_{F D}=\sum_{i=1}^{n} S_{i, \text { new }} \text {. }
$$

\section{Results}

Let us consider the process of foresight of innovation system development using a multi-objective genetic algorithm as exemplified by the Volga Federal District (VFD) of the Russian Federation.

According to the list approved by the Government of the Russian Federation, there were 25 pilot innovative territorial clusters operating in the regions of the Russian Federation. Then, we only considered those VFD areas (regions or republics) where the clusters from this list are located (Table 1).

Table 1 Innovative territorial clusters by regions of the Volga Federal District

\begin{tabular}{ll}
\hline \multicolumn{1}{c}{ Regions } & \multicolumn{1}{c}{ Innovative clusters } \\
\hline 1) Nizhny Novgorod Region & $\begin{array}{l}\text { Nizhny Novgorod industrial innovative cluster in automotive and petrochemical } \\
\text { engineering }\end{array}$ \\
2) Republic of Mordovia & Energy-efficient lighting engineering and smart lights \\
3) Ulyanovsk Region & ULYANOVSK-AVIA Scientific and Educational Production Cluster consortium \\
& Dimitrovgrad nuclear innovation cluster \\
4) Samara Region & Innovative territorial aerospace cluster \\
5) Perm Territory & NOVY ZVEZDNY Technopolis innovative territorial cluster of rocket engine \\
& building \\
6) Udmurt Republic & Photonics \\
7) Republic of Tatarstan & Udmurt machine building cluster \\
8) Republic of Bashkortostan & Kama innovative territorial production cluster \\
\hline
\end{tabular}

Stage 1. Using the "Statistical Review" of the Federal State Statistics Service (www.gks.ru), we grouped the necessary data on the natural population growth $(z)$, average per capita monetary income of the population (per month) $\left(y_{1}\right)$, investment in equity $\left(y_{2}\right)$, and internal current expenditures on $R \& D\left(y_{3}\right)$ for 10 years from 2009 to 2018. At the same time, for the sake of comparability of the data, we adjusted the indicators measured in rubles for inflation (Table 2). As a result, we obtained a data matrix for foresight of the 
dimensional product 80 by 4 in 2018 prices (Table 3). This table shows data for the Nizhny Novgorod region only.

Table 2 Annual rates of inflation (\%)

\begin{tabular}{cccccccccc}
\hline & 2010 & 2011 & 2012 & 2013 & 2014 & 2015 & 2016 & 2017 & 2018 \\
\hline Ruble & 8.78 & 6.1 & 6.58 & 6.45 & 11.36 & 12.91 & 5.38 & 2.52 & 4.27 \\
\hline
\end{tabular}

Table 3 Foresight data in 2018 prices

\begin{tabular}{ccccc}
\hline Region & $\begin{array}{c}\text { Average per capita } \\
\text { cash income of } \\
\text { population (per } \\
\text { month) (RUB) }\end{array}$ & $\begin{array}{c}\text { Investment in } \\
\text { equity } \\
\text { (million RUB) }\end{array}$ & $\begin{array}{c}\text { Internal current } \\
\text { expenditures on } \\
\text { R\&D (million } \\
\text { RUB) }\end{array}$ & $\begin{array}{c}\text { Natural } \\
\text { growth of } \\
\text { population } \\
\text { (persons) }\end{array}$ \\
\hline Nizhny Novgorod Region & $y_{1}$ & $y_{2}$ & $y_{3}$ & $Z$ \\
2009 & $26,646.5$ & $364,200.0$ & $41,456.1$ & $-22,094$ \\
2010 & $27,399.0$ & $293,805.4$ & $46,022.7$ & $-22,942$ \\
2011 & $28,948.2$ & $356,243.3$ & $48,495.1$ & $-17,869$ \\
2012 & $32,204.6$ & $389,268.9$ & $57,557.7$ & $-13,890$ \\
2013 & $34,216.8$ & $385,562.5$ & $52,691.9$ & $-13,457$ \\
2014 & $35,548.8$ & $364,555.9$ & $66,121.7$ & $-12,846$ \\
2015 & $34,663.1$ & $257,909.3$ & $64,064.0$ & $-10,714$ \\
2016 & $32,503.3$ & $234,809.1$ & $70,891.4$ & $-11,420$ \\
2017 & $31,967.1$ & $254,493.0$ & $67,023.1$ & $-13,556$ \\
2018 & $31,631.0$ & $259,045.4$ & $66,202.2$ & $-15,917$ \\
\hline
\end{tabular}

Stage 2. For this purpose, we used the Internet service WolframAlpha (www.wolframalpha.com). For instance, for the Nizhny Novgorod region, we obtained three best predictive functions for $y_{1}$ using the data from Table 3 . The highest determination coefficient $R^{2}=0.988022$ was attributed to the polynomial of Degree 4 , so it was accepted as the best predictive function. The predictive functions for $y_{2}$ and $y_{3}$ were obtained in a similar way.

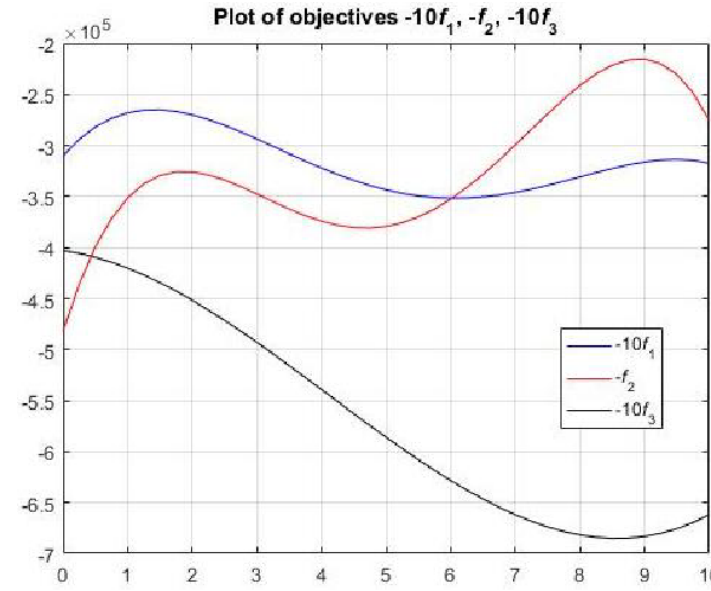

a)
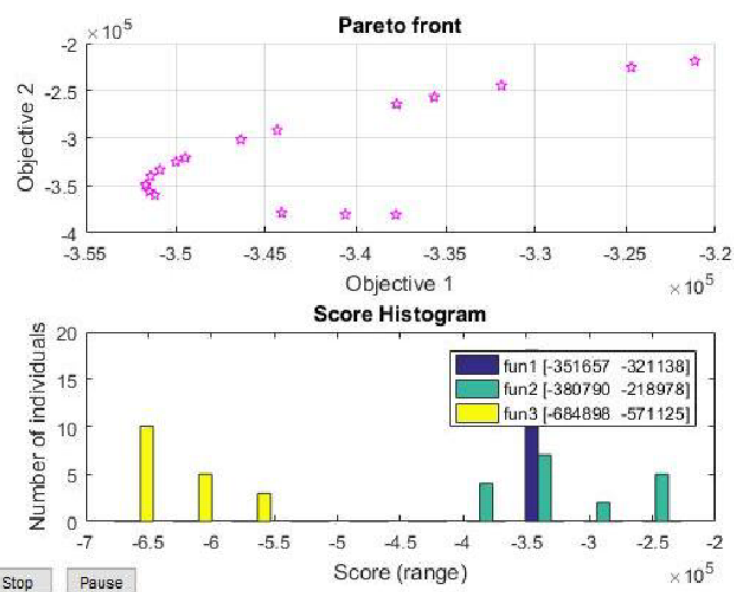

b)

Figure 2 Graphs of functions $y_{1}, y_{2}$, and $y_{3}(\mathrm{a})$ and Pareto frontier between optimal $y_{1}$ and $y_{2}$ (b)

The predictive functions $y_{1}, y_{2}$, and $y_{3}$ were produced on a single graph in Matlab (Figure 2a). Since the Matlab software in which the multi-objective genetic algorithm was implemented only solves minimum problems, all three graphs were inverted. Thus, we minimized negative functions. In addition, we multiplied two of the three functions by 10 for clarity. 
In light of this, Figure 2a shows that we looked for minimums for the three functions simultaneously. The Pareto frontier we needed was located between the extreme lows out of the three, i.e., approximately in the segment [4.5, 8.5] along the horizontal axis.

Stage 3. To implement the multi-objective genetic algorithm, an $M$ file function was created. Then, we constructed the required Pareto frontier between the optimal $y_{1}$ and $y_{2}$ (Figure 2b). Similarly, it was possible to obtain the Pareto frontier between the optimal $y_{1}$ and $y_{3}$ (Figure 3a) and between the optimal $y_{2}$ and $y_{3}$ (Figure 3b). Additionally, Figures 2-3 show the intervals from the global extremum of each analyzed function to the other limiting extremum of the corresponding graph function. These intervals were used at the next foresight stage.
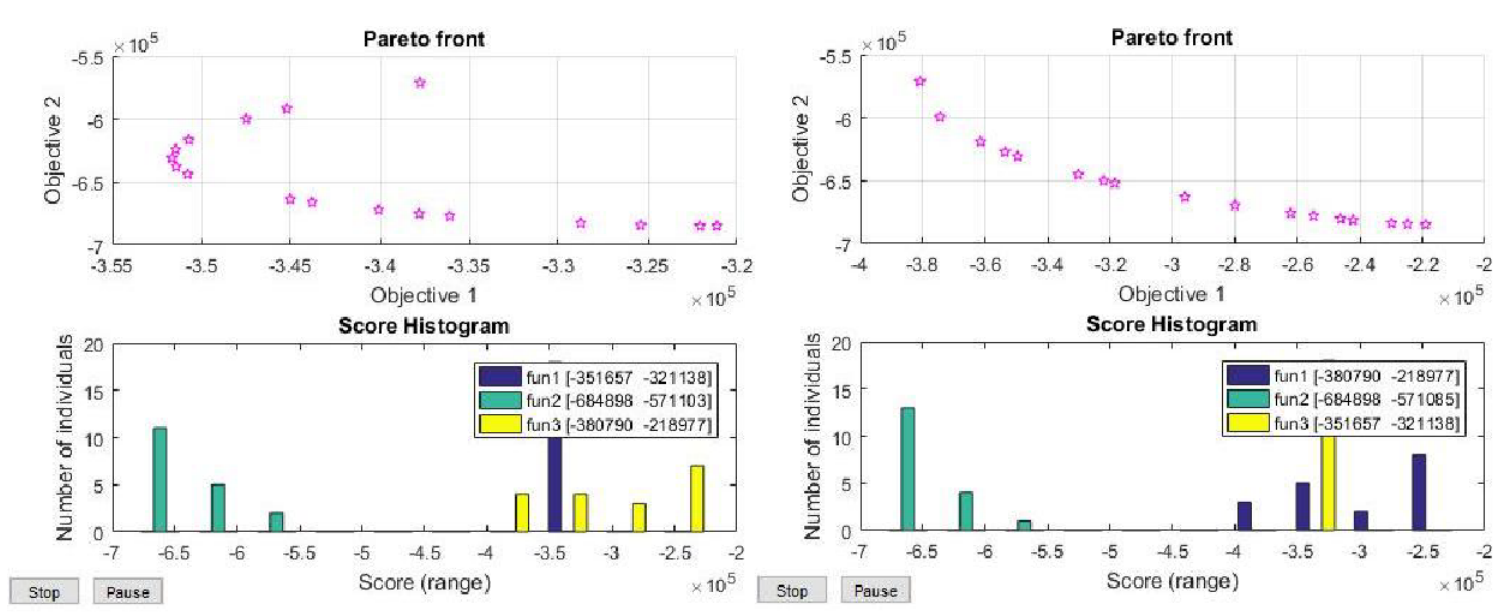

a)

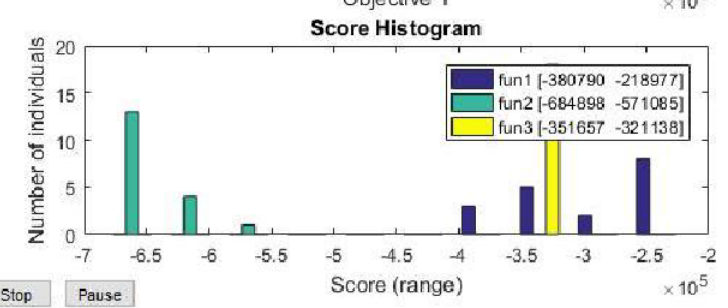

b)

Figure 3 Pareto frontier between optimal $y_{1}$ and $y_{3}$ (a) and between optimal $y_{2}$ and $y_{3}$ (b)

As mentioned earlier, all the solutions shown at the Pareto frontier are optimal. However, we were interested in a situation where the population of the region would have the maximum average per capita income. This imposed serious adjustments to the Pareto frontier analysis process. For instance, Figure $2 \mathrm{~b}$ shows that when moving along the optimal Pareto frontier in the direction of increasing the investment in equity $\left(y_{2}\right)$, the population income first grows up, then slightly grows down. This suggests that the Nizhny Novgorod Region has an optimal amount of investment, above which the income of the population will decline, which will eventually lead to a decrease in the rate of population growth in the region.

By analyzing the Pareto frontier in Figure 3a, a similar conclusion was with respect to expenditures on R\&D in the region $\left(y_{3}\right)$. Moving along the Pareto frontier in the direction of increasing expenditures on $\mathrm{R} \& \mathrm{D}$, the income of the population at first slightly increased, and then significantly decreased. This means that even more caution should be exercised with regard to financing R\&D in the Nizhny Novgorod Region. One cannot exceed the optimal R\&D shown at the Pareto frontier.

As for the graph analysis in Figure $3 b$, the situation here was more transparent. Investment in equity and expenditures on $R \& D$ are competing goals, which seems to be quite natural, since it is impossible to finance successfully, i.e., with good performance, the fundamental costs with a potential effect over a long period of time, i.e., R\&D, and current manufacturing requirements, i.e., investment in equity, simultaneously.

Consequently, the takeaway for the Nizhny Novgorod Region at the current stage of foresight according to Figures 2-3 was that there were optimum investments in equity and $\mathrm{R} \& \mathrm{D}$ in this region to obtain the maximum income of the population. 
The takeaways obtained in a similar way at this stage of foresight for all 8 regions of the VFD, where the presence of innovative and industrial clusters, as grouped in Table 4.

Table 4 Takeaways for 8 VFD regions based on analysis of Pareto frontiers of predictive functions

\begin{tabular}{ll}
\hline \multicolumn{1}{c}{ Regions } & \multicolumn{1}{c}{ Takeaways } \\
\hline 1) Nizhny Novgorod Region & $\begin{array}{l}\text { There are optimum investment and R\&D to maximize the income of the } \\
\text { population. }\end{array}$ \\
2) Republic of Mordovia & $\begin{array}{l}\text { Investments need to be reduced, and R\&D needs to be increased to maximize } \\
\text { the income of the population. } \\
\text { The investment should be raised first, then slightly reduced. The R\&D has to be } \\
\text { reduced. }\end{array}$ \\
3) Ulyanovsk Region & $\begin{array}{l}\text { Investments need to be reduced, and R\&D needs to be increased to maximize } \\
\text { the income of the population. }\end{array}$ \\
4) Samara Region & $\begin{array}{l}\text { Investments should be reduced and R\&D increased, then slightly reduced. } \\
\text { Investments and R\&D need to be reduced to maximize the incomes of the } \\
\text { p) Perm Territory }\end{array}$ \\
6) Udmurt Republic & $\begin{array}{l}\text { Investments need to be increased and R\&D decreased to maximize the incomes } \\
\text { of the population. }\end{array}$ \\
7) Republic of Tatarstan & $\begin{array}{l}\text { Investments need to be reduced, and R\&D needs to be increased to maximize } \\
\text { the incomes of the population. }\end{array}$ \\
8) Republic of Bashkortostan &
\end{tabular}

Stage 4. We performed the calculations based on the results of the previous foresight stage in Table 5 according to formula 1.

Stage 5. The Samara Region had the largest shortage of current expenditures on R\&D compared to the optimal plan. It amounted to 10,673 million rubles. It can be partially filled up at the expense of reserves for R\&D in the Nizhny Novgorod and Ulyanovsk regions, the Udmurt Republic, and the republics of Tatarstan and Bashkortostan. The total amount of such reserves was 8,412 million rubles. It should be forwarded to the Samara Region. Then, its synergy effect according to formula 2 would be:

$S_{\text {new }}=343,045-259,152.3+24,419.4-13,746.4-8.412=86,153.7$ (million rubles).

Adding up the results of the last column of Table 5, we obtained formula 3, so that the synergy effect of the whole VFD was $S_{F D}=429,344$ million rubles.

Table 5 Calculation of synergy effects of clusters and the entire VFD

\begin{tabular}{|c|c|c|c|c|c|c|c|}
\hline \multicolumn{2}{|c|}{$\begin{array}{c}\text { Average per capita cash } \\
\text { income of population (per } \\
\text { month) (RUB) }\end{array}$} & \multicolumn{2}{|c|}{$\begin{array}{l}\text { Investment in equity } \\
\text { (million RUB) }\end{array}$} & \multicolumn{2}{|c|}{$\begin{array}{c}\text { Internal current } \\
\text { expenditures on R\&D } \\
\text { (million RUB) }\end{array}$} & \multicolumn{2}{|c|}{$\begin{array}{c}\text { Synergy effect (million } \\
\text { RUB) }\end{array}$} \\
\hline Plan & Actual & Plan & $\begin{array}{c}\text { Actual } \\
\text { 1) Nizhny No }\end{array}$ & $\begin{array}{c}\text { Plan } \\
\text { od Region }\end{array}$ & Actual & Plan & Reserve \\
\hline $35,165.7$ & 31,631 & 350,000 & $\begin{array}{l}259,045.4 \\
\text { 2) Republic }\end{array}$ & $\begin{array}{r}63,000 \\
\text { Iordovia }\end{array}$ & $66,202.2$ & $87,752.4$ & $3,202.2$ \\
\hline $20,189.9$ & 18,048 & $70,032.2$ & $\begin{array}{l}51,210.1 \\
\text { 3) Ulyano }\end{array}$ & $\begin{array}{l}1,075 \\
\text { Region }\end{array}$ & 970.7 & $18,926.4$ & -104.3 \\
\hline $26,447.4$ & 22,846 & 108,000 & $\begin{array}{l}81,105.4 \\
\text { 4) Sama }\end{array}$ & $\begin{array}{l}9,901.5 \\
\text { egion }\end{array}$ & $11,291.2$ & $25,504.9$ & $1,389.7$ \\
\hline $36,356.8$ & 27,507 & 343,045 & $\begin{array}{r}259,152.3 \\
5) \text { Perm }\end{array}$ & $\begin{array}{l}24,419.4 \\
\text { itory }\end{array}$ & $13,746.4$ & $86,153.7$ & $-10,673$ \\
\hline $36,845.6$ & 28,777 & 244,113 & $\begin{array}{r}238,007.9 \\
\text { 6) Udmu }\end{array}$ & $\begin{array}{l}14,100 \\
\text { public }\end{array}$ & $12,754.5$ & $7,450.6$ & $-1,345.5$ \\
\hline $27,225.2$ & 24,415 & 102,100 & $\begin{array}{l}\text { 97,892.8 } \\
\text { 7) Republic }\end{array}$ & $\begin{array}{r}1,320.8 \\
\text { atarstan }\end{array}$ & $2,295.3$ & $3,233.7$ & 974.5 \\
\hline $37,271.1$ & 33,130 & 723,603 & $\begin{array}{c}629,731 \\
\text { 8) Republic of }\end{array}$ & $\begin{array}{c}14,200 \\
\text { hkortosta }\end{array}$ & $17,038.8$ & $91,033.2$ & $2,838.8$ \\
\hline $33,294.9$ & 28,645 & 377,164 & $267,868.1$ & 10,350 & $10,356.8$ & $109,289.1$ & 6.8 \\
\hline
\end{tabular}




\section{Discussion}

Based on the analysis of the Pareto frontiers of predictive functions we obtained the following insights:

1. The Nizhny Novgorod Region had a limit of optimal investments and R\&D, above which it was impossible to develop the region.

2. The greatest benefit from R\&D was seen for the Republic of Mordovia, Samara Region, and Republic of Bashkortostan.

3. The Republic of Tatarstan was the most investment-attractive region, provided that R\&D of the other VFD regions was open.

It was also possible to partially allocate the reserve of 8,412 million rubles for R\&D to the Republic of Mordovia and Perm Territory, and the rest to the Samara Region. However, the synergy effect of the entire VFD, in this case, was the same as if the total reserve was allocated for R\&D in the Samara Region.

Such redistribution of resources within the VFD enabled it to reach the planned indicators of average per capita cash incomes of the population (per month), which are shown in the first column of Table 5. In turn, this will lead to the maximum values of natural population growth in the VFD regions, which can be quite easily found for each of the 8 analyzed regions in Table 1.

This paper contributed to the development of methods for assessing regional cluster performance, considering their interconnectedness and present approach that is different from expert assessment, which can be used when the information about cluster development is limited (Kudryavtseva et al., 2020a), and from classical approaches, which are based on estimation of relative concentration of the industries in the region (Delgado et al., 2014; Skhvediani et al., 2020). Application of optimization algorithms will estimate synergy effects for the regions, where clusters are located, and elaborate more scientificbased regional cluster policies.

\section{Conclusion}

This paper presented novel approach to the assessment of regional cluster performance using genetic algorithms. From the theoretical point of view, we presented stages of foresight, including preparation of statistical data for clusters, obtaining predictive functions for clusters and Pareto frontiers of predictive functions, and planning of synergy effects of clusters of regions and the entire federal district. From a practical point of view, this study resulted in the estimation of the reserve for R\&D for the Volga Federal District based on the data of 25 clusters from 2009-2018. As a result of foresight, we estimated a total positive reserve for $R \& D$ in the amount of 8,412 million rubles, which should be forwarded to the Samara Region. Then, the synergy effect of the entire VFD would be equal to 429,344 million rubles.

\section{Acknowledgements}

This paper has been accomplished within the framework of the basic part of the state task of the Ministry of Education and Science of the Russian Federation, project 0729-20200056 "Modern methods and models of diagnostics, monitoring, prevention and overcoming of crisis phenomena in the economy under conditions of digitalization as a way to ensure economic security of the Russian Federation". 


\section{References}

Ahuja, R.K., Orlin, J.B., Tivari, A., 1995. A Greedy Genetic Algorithm for the Quadratic Assignment Problem. Working Paper Sloan School of Management, Volume 2, pp. 13-17

Chen, Y., Feng, C., Wang, Y., Wu, H., 2011. Using BIM Model and Genetic Algorithms to Optimize the Crew Assignment for Construction Project Planning. International Journal of Technology, Volume 2(3), pp. 179-187

Delgado, M., Porter, M.E., Stern, S., 2014. Clusters, Convergence, and Economic Performance. Research Policy, Volume 43(10), pp. 1785-1799

Delgado, M., Porter, M.E., Stern, S., 2016. Defining Clusters of Related Industries. Journal of Economic Geography, Volume 16(1), pp. 1-38

Holland, J.H., 1992. Adaptation in Natural and Artificial Systems: An Introductory Analysis with Applications to Biology, Control, and Artificial Intelligence. Cambridge: The MIT Press

Kalyanmoy, D., 2001. Multiobjective Optimization using Evolutionary Algorithms. New York: John Wiley \& Sons, Inc

Ketels, C., Protsiv, S., 2020. Cluster Presence and Economic Performance: A New Look Based on European Data. Regional Studies, 10 Aug 2020, pp. 1-13

Kravets, O.Y., Safronova, A.P., 2013. Overview of Structural Synthesis Methods to Solve Quadratic Assignment Problems. Modern Science: Current Problems of Theory and Practice: Scientific and Practical Journal: Series Natural and Economic Sciences, Volume 9(10), pp. 66-72

Kudryavtseva, T., Kulagina, N., Lysenko, A., Berawi, M.A., Skhvediani, A., 2020a. Developing Methods to Assess and Monitor Cluster Structures: The Case of Digital Clusters. International Journal of Technology, Volume 11(4), pp. 667-676

Kudryavtseva, T., Skhvediani, A., Berawi, M.A., 2020b. Modeling Cluster Development using Programming Methods: Case of Russian Arctic Regions. Entrepreneurship and Sustainability Issues, Volume 8(1), pp. 150-176

Martin, B.R., 1983. Project Foresight, a Proposal Submitted to the Cabinet Office. Brighton, UK: SPRU, University of Sussex

Martin, B.R., 1989. Research Foresight: Priority-setting in Science. London and New York: Pinter Publishers

Martin, B.R., 2010. The Origins of the Concept of 'Foresight' in Science and Technology: An Insider's Perspective. Technological Forecasting and Social Change, Volume 77(9), pp. 1438-1447

Michalewicz, Z., 1996. Genetic Algorithms + Data Structures = Evolution Programs. New York: Springer-Verlag

Morov, V.A., 2012. Application of the Genetic Algorithm to Optimization Problems. Implementation of the Genetic Algorithm for the Traveling Salesman Problem. Journal of the Amur State University: Series Natural and Economic Sciences, Volume 57, pp. 1822

Nasruddin, Nasution, S., Aisyah, N., Surachman, A., Wibowo, A.S., 2018. Exergy Analysis and Exergoeconomic Optimization of a Binary Cycle System using a Multi Objective Genetic Algorithm. International Journal of Technology, Volume 9(2), pp. 275-286

Rodionov, D., Velichenkova, D., 2020. Relation between Russian Universities and Regional Innovation Development. Journal of Open Innovation: Technology, Market, and Complexity, Volume 6(4), pp. 118-144

Rutkowska, D., Pilinski, M., Rutkowski, L., 1999. Sieci Neuronowe, Algorytmy Genetyczne $i$ Systemy Rozmyte. Warszawa, Lodz: Wydawnictwo Naukowe PWN 
Rytova, E., Gutman, S., 2020. Assessment of Regional Development Strategy in the Context of Economy Digitization on the Basis of Fuzzy Set Method. IOP Conference Series: Materials Science and Engineering, Volume 497(1), pp. 12-60

Skhvediani, A., Kudryavtseva, T., Rodionov, D. 2020. Regional Industrial Specialization: Case of Russian Electrical Equipment, Electronic and Optical Equipment Industry. In: Rodionov D., Kudryavtseva T., Berawi M.A., Skhvediani A. (eds) Innovations in Digital Economy. SPBPU IDE 2019. Communications in Computer and Information Science, Volume 1273. Springer, Cham, pp. 125-139

Snytyuk, V.Y., Suprun, O.O., 2017. Evolutionary Clustering as Technique of Economics Problems Solving. Electronics and Control Systems, Volume 4(54), pp. 95-101

Stepanova, E.V., 2019. Evaluation of Innovation Potential in Russian Clusters. IOP Conference Series: Earth and Environmental Science, Volume 315(2), pp. 22-91

Tate, D.M., Smith A.E., 1995. A Genetic Approach to the Quadratic Assignment Problem. Computers \& Operations Research, Volume 22(1), pp. 73-83

Tukkel, I.L., Golubev, S.A., Surina, A.V., Tsvetkova, N.A., 2013. Methods and Tools of Innovative Development of Industrial Enterprises. St.-Petersburg: BHV-Petersburg

Yashin, S.N., Trifonov, Yu.V., Koshelev, E.V., 2017. Methods of Foresight of the Cluster using the Arbitrage Technology. Innovations, Volume 11, pp. 42-53

Yashin, S.N., Koshelev, E.V., Kostrigin, R.V., 2019. Compilation of Linear Functional of the Value of the Innovation and Industrial Cluster for the Region. Management of Economic Systems: Scientific Electronic Journal, Volume 130(12), pp. 1-19 